\title{
Assessing discrimination in correspondence studies
}

Jorge Rodriguez-Menes

Department of Political and Social Sciences, Universitat Pompeu Fabra, Barcelona, Spain

Marti Rovira

Department of Sociology and Nuffield College, University of Oxford, United Kingdom, and Department of Law, Universitat Pompeu Fabra, Barcelona, Spain

\begin{abstract}
Correspondence studies are popular tools for assessing discrimination against minorities, for example, in the labor market. Typically, two fake CVs are sent to multiple job openings. The CVs are equivalent except for a mark identifying the disadvantaged. While it is straightforward to establish discrimination from minorities' lower response rates, it is often unclear what its source may be. Discrimination may result as much from employers' aversion towards a minority, as from perceptions that members have lower or more dispersed abilities that are unstandardizable in a CV. We refine existing methodologies to propose a wider-scope method capable of disentangling these three sources of discrimination, and establish its face validity applying it to a correspondence study aimed at assessing labor market discrimination against ex-convicts in a local market.
\end{abstract}




\section{Introduction}

Audit studies are increasingly popular tools for assessing discrimination in employment (Pager 2003; Bertrand and Mullainathan 2004), housing decisions (Ewens, Tomlin, and Wang 2014), credit approvals (Dymski 2006), or consumer market transactions (Rich 2014). Typically, two demands (for a job, rental, credit, or product), are sent to a random sample of decision-makers from fake applicants. Applicants' merits are matched in everything, except their having or not a trait which may trigger the discriminatory practices that the experimenter aims to observe from decision-makers. This trait is generally a mark/stigma signaling membership into a socially disadvantaged group - a minority, thereafter ${ }^{1}$ - such as women (Correll, Benard, and Paik 2007), an ethnic group (Pager 2003; Booth, Leigh, and Varganova 2012), or ex-convicts (Uggen et al. 2014). If decisions on the applications are significantly less favorable for minorities, discrimination is established.

The main difficulty in audit studies is not to find discrimination but to identify its various sources: from an aversion towards minorities - taste discrimination (Becker 1971) - to rational assessments about differences between minority and majority members in typical productivities - first-moment statistical discrimination - or in the variability of such productivities within groups - second-moment statistical discrimination (Heckman and Siegelman 1993; Heckman 1998; Neumark 2012).

While there have been some proposed solutions to distinguish taste from first-moment statistical discrimination - see, for example, Altonji and Perriet (2001), Lahey (2008), or Ewens, Tomlin, and Wang (2014) - and these two from second-moment statistical discrimination (Neumark 2012), to this date a comprehensive approach combining them into a single method does not exist. The main contribution of this article is to propose such a method, one that allows estimating the three forms of discrimination provided some (testable) assumptions hold. We demonstrate its validity for the simplest form of an audit

\footnotetext{
${ }^{1}$ Minority is meant here to indicate a group' lower status, not its demographic size.
} 
study - a correspondence study in which the outcome is to be or not to be selected for further screening - and for discrimination in the labor market.

The article is organized as follows. In the first part, we follow Heckman and Siegelman (1993), Heckman (1998), and Neumark (2012) to formalize the problems for separating the three forms of discrimination. In the second part, we review the existing solutions to these problems, and propose our own. In the third part of the paper we show method's usefulness by applying it to data from a correspondence study aimed at detecting discrimination against ex-convicts in a local labor market. Method's strengths and weaknesses are discussed in the final section.

\section{Taste discrimination}

Taste discrimination is typically defined as resulting from prejudice - a response expressing animus or aversion against an out-group that is not based on reason, but on emotion (Lang and Lehman 2012).

Aversion is just one among the possible factors accounting for employers' decisions to select a candidate for further screening. Heckman and Siegelman (1993) and Heckman (1998) proposed a probabilistic model of employers' decision-making in which their selection decisions depend not only on prejudicial assessments of candidate's appeal to employers, but also on objective evaluations of candidate's potential productivity. These evaluations are partly based on qualifications that can be standardized in a CV - on "observables". They also depend on error-prone guesses about candidates' unstandardizable qualifications - "unobservables" - based on clues rooted in experience. 
More formally: let employer's decision $Y$ to select a candidate for a job interview depend on an underlying continuous variable $Y^{*}$ capturing candidate's appeal to employers. ${ }^{2}$ This appeal varies according to candidate's productivity $P$, such that $Y^{*}(P)$. Candidates will be selected $(y=1)$, if their appeal equals or exceeds a minimum cutoff level $c$ set by the employer (if $Y^{*} \geq c$ ). Let candidate's productivity, in turn, depend on a set of candidate's observable $\left(X_{1}\right)$ and unobservable $\left(\tilde{X}_{2}\right)$ qualifications, and on firm's $F$ characteristics, such that $P\left(X_{1}, \tilde{X}_{2}, F\right)$. Thus:

$$
Y\left(Y^{*}\left(P\left(X_{1}, \tilde{X}_{2}, F\right)\right)\right)=1 \text { if } Y^{*} \geq c, \text { and } Y=0 \text { otherwise }
$$

Correspondence studies hypothesize that candidates' appeal depends both on their productivities $(P)$ and on group membership $(G)$. Minorities are less appealing and less likely to be selected than other candidates. Thus, under the alternative hypothesis:

$$
Y\left(Y^{*}\left(P\left(X_{1}, \tilde{X}_{2}, F\right), G\right)\right)
$$

If we assume, for simplicity, that $Y^{*}$ is linear on $P$ and $G$, and that candidates' productivity-related qualifications are uncorrelated with group membership $[\operatorname{Cov}(P, G)=0]$, we can rewrite $Y^{*}$ in 1 a as:

$$
Y^{*}=P+\gamma G
$$

If minority candidates are coded as $1(g=1)$ and the other candidates as $0(g=0)$, the expectation is that $\gamma$ will be negative when averaged across jobs, and that the cutoff applied to minorities will be higher than that applied to the advantaged, due to employers' aversion towards the former. Hence:

$$
Y=1 \text { if } P+\gamma G \geq c \equiv \text { if } P \geq c-\gamma G, \text { and } Y=0 \text { otherwise }
$$

\footnotetext{
${ }^{2}$ Our notation follows closely Heckman's (1998) and Neumark's (2012).
} 
In sum: employers who discriminate minorities because they distaste them apply two cutoffs: $c$ for the majority and $c-\gamma$ for the minority. ${ }^{3} \gamma$ is both a measure of the discrimination faced by minorities and the extra productivity they need to display to have the same appeal to employers as non-minorities.

Heckman and Siegelman (1993) argued against interpreting differences in minorities and non-minorities' appeal to employers in correspondence studies as unequivocally capturing taste discrimination, due to undesired selection effects that cannot be effectively controlled with matching. Matching guarantees that the paired candidates demanding a job are equivalent on observables, except for the mark signaling membership into the minority. However, nothing guarantees that employers perceive the pair as having similar unobservables. Perceptions about the distributions of unobservables across groups, rather than aversion, may lead employers to discriminate against minorities. These perceptions may be about group differences in the mean levels or the dispersion of unobservables. The former lead to first-moment statistical discrimination; the latter, to second-moment statistical discrimination.

\section{First-moment statistical discrimination}

"First-moment statistical discrimination" (Neumark 2012) is typically portrayed as stemming from rational assessments of in- and out-groups' stereotypical qualifications, as derived from experience (Levitt 2004). One first manifestation is when employers perceive the mean of the unobservables in the minority to differ from non-minorities'.

As assumed above and demonstrated by Heckman (1998), to estimate $\gamma$ without bias, a key assumption rarely spelled out in correspondence studies must hold - group membership and productivity must be independent $(P \perp G)$. This holds for candidates' $X_{1}$ observables, which experimenters match across

\footnotetext{
${ }^{3} c-\gamma$ will be higher than $c$ if, as expected, $\gamma$ is negative.
} 
groups, but might not hold for productivity-linked $\tilde{X}_{2}$ characteristics unobserved to experimenters but acted upon by employers. Two reasons explain it.

Suppose, for simplicity, that as in Heckman (1998), candidates' productivities - on which employers base their selection decisions - are a linear function of, first, individuals' $X_{1}$ observables and second, of their $\tilde{X}_{2}$ unobservables.

$$
P=X_{1}+\tilde{X}_{2}
$$

We place a tilde above $\tilde{X}_{2}$, the set of unobservables, to indicate that they pertain to all members of a group. Employers do not know candidates' personal characteristics if omitted from the CVs. Any unobserved characteristic attributed to them must come from pre-conceptions about group members' average productivity and typical dispersions.

In a correspondence study, experimenters fix candidates' observables in the CVs, generally at similar levels across job offers, as they are not interested in estimating the effect of $X_{1}$ observables on productivity, but in establishing differences in selection rates between groups. By making observables equivalent across groups, experimenters ensure they are independent of group membership.

Let the relationship between productivity and candidates' characteristics be deterministic ${ }^{4}$ regarding $X_{1}$ but probabilistic regarding $\tilde{X}_{2}$. When employers are randomly selected for a correspondence study, their perceptions about candidates' unobservables can be seen as defining the sampling distribution of candidates' unobserved productivities. Let assume that employers' perceptions of the productivities derived from candidates' $\tilde{X}_{2}$ unobservables are normally distributed around the mean $\mu_{\tilde{X}_{2}}$ corresponding to productivity level $p_{b}$ - where the subscript $b$ stands for "baseline" -, with a variance of $\sigma_{\tilde{X}_{2}}^{2}$.

\footnotetext{
${ }^{4}$ Considering the relationship to be probabilistic only complicates the exposition, without changing its substance.
} 


$$
\tilde{X}_{2} \sim N\left(\mu_{\tilde{X}_{2}}, \sigma_{\tilde{X}_{2}}^{2}\right)
$$

Put differently, the productivities corresponding to candidates' $\tilde{X}_{2}$ unobservables can be decomposed into a constant $p_{b}$ capturing employers' perceptions of candidates' average productivity associated with unobservables, and an idiosyncratic error $\varepsilon_{i}$ expressing the typical error in such perceptions. Hence, the prediction equation for $P$ derived from 4 above is:

$$
\begin{gathered}
P_{i}=p_{b}+X_{1}+\varepsilon_{i} \\
\text { where } p_{b}=E\left(P \mid \tilde{X}_{2}, X_{1}=0\right)=E\left(\tilde{X}_{2}\right)=\mu_{\tilde{X}_{2}}
\end{gathered}
$$

Let's assume that employers perceive the means of the normal distributions of unobservable-related productivities to be the same for minorities and non-minorities, i.e., that $E\left(\tilde{X}_{2}^{0}\right)=E\left(\tilde{X}_{2}^{1}\right)$ (superscripts 0 and 1 stand, respectively, for nonminorities and minorities), because like observables, unobservables are also independent of group membership $\left(\tilde{X}_{2} \perp G\right)$. If the assumption held and taste discrimination was the reason behind minorities' lower selection rates, the prediction equation 2 for the underlying variable regulating selection probabilities could be rewritten as:

$$
Y_{i}^{*}=p_{b}+X_{1}+\gamma^{\prime} G+\varepsilon_{i}
$$

However, if employers thought that minorities have lower (or higher) average productivities linked to unobservables than other candidates $\left(E\left(\tilde{X}_{2}^{1}\right)<E\left(\tilde{X}_{2}^{0}\right)\right), \gamma^{\prime}$ would capture, at least partly, employers' beliefs about these group differences in average productivities (hence the prime superscript). This can be formalized as:

$$
\tilde{X}_{2_{i}}=p_{b}+\varepsilon_{i}=p_{b}+\delta G+\tau_{i}
$$


where $E\left(\tau_{i}\right)=0$, and where $\delta$ equals the difference between minority and majority candidates in their appeal to employers because of their differences in unobservables. ${ }^{5}$

One possibility not contemplated in Heckman's (1998) formalization of first-moment statistical discrimination is that employers may believe that the contribution of unobservables to productivity is different in each group. ${ }^{6}$ For example, they might think that hiring minorities may affect negatively the productivities of others workers who hold prejudices against them - see Ewens, Tomling and Yang (2014) for a similar formalization. These beliefs about the different contribution of unobservables' to groups' productivities may be important in shaping employers' assessments of their different productivities. If these beliefs exist, then:

$$
\tilde{X}_{2_{i}}=p_{b}+\varepsilon_{i}=p_{b}+\delta G+\lambda G+\tau_{i}
$$

where $\lambda$ equals the difference between minorities and non-minorities in the effect of unobservables on productivities.

Correspondingly, a candidate's score on the underlying scale of appeal to employers will be:

$$
Y_{i}^{*}=p_{b}+X_{1}+\delta G+\lambda G+\gamma G+\tau_{i}=p_{b}+X_{1}+(\gamma+\delta+\lambda) G+\tau_{i}
$$

If 10 holds, $\gamma^{\prime}$ in equation 7 , which supposedly estimated employers' lower sympathy towards minorities, was biased because it included employers' perceived differences ( $\delta$ and $\lambda)$ in minorities' productivities relative to non-minorities $\left(\gamma^{\prime}=\gamma+\delta+\lambda\right)$.

\footnotetext{
${ }^{5}$ These differences in appeal will equal the differences in groups' mean levels of unobservables $\left(\bar{X}_{2}^{1}-\bar{X}_{2}^{0}\right)$ when $\widetilde{X}_{2}$ is standardized.

${ }^{6}$ The argument applies also to observables, in which case the matching of candidates on observables performed in audit studies cannot accomplish what it intends to.
} 


\section{Second-moment statistical discrimination}

A second problem in correspondence studies is experimenters' implicit assumption that the variance in employers' perceptions of candidates' unobservables is the same among nonminorities and minorities:

$$
\operatorname{Var}\left(\tilde{X}_{2}^{0}\right)=\operatorname{Var}\left(\tilde{X}_{2}^{1}\right)
$$

However, employers may perceive that minorities differ more (or less) among themselves in unobservables than non-minorities. For example, experimenters may feel more uncertain about candidates' unobservables when they belong to groups they know less. As argued by Heckman (1998), if employers perceived groups' distributions of unobservables as being normally distributed but having different variances, their perceptions would result in different callback probabilities for each group, even if they applied the same selection cutoff to both and thought that both have the same average levels of unobservables (i.e., even if there was neither taste not first-moment statistical discrimination). ${ }^{7}$

When groups' variances differ, it is difficult to predict which group will experience a lower callback probability, for this will depend on whether employers' selection cutoff is below or above the mean of candidates' unobservables, and on which group has higher variance. Our problem is how to distinguish this second-moment statistical form of discrimination from the other types.

Suppose that employers exert taste discrimination against minorities but not first-moment statistical discrimination. Further suppose that, as assumed in a typical correspondence study, $\operatorname{Var}\left(\tilde{X}_{2}^{0}\right)=$

\footnotetext{
${ }^{7}$ Except in the improbable case that the cutoff were located exactly at the means of the two distributions of unobservables.
} 
$\operatorname{Var}\left(\tilde{X}_{2}^{1}\right)$. Then, combining expressions 1 and 6 above, a candidate's callback probability could be written as in a standard probit model:

$$
\begin{gathered}
\operatorname{Pr}(Y=1)=\operatorname{Pr}\left(Y^{*}>c \mid X_{1}, \tilde{X}_{2}, G\right)=\operatorname{Pr}\left(p_{b}+X_{1}+\gamma G+\varepsilon_{i}>c\right)= \\
\operatorname{Pr}\left(\varepsilon_{i}>c-\left(p_{b}+X_{1}+\gamma G\right)\right)
\end{gathered}
$$

To identify the probit coefficients, they must be expressed in units of standard deviation of, in our case, the random variable $\tilde{X}_{2}$ capturing candidates' unobservables:

$$
\operatorname{Pr}(Y=1)=\operatorname{Pr}\left(\frac{\varepsilon_{i}}{\sigma_{\tilde{X}_{2}}}>-\frac{p_{b}+X_{1}+\gamma G-c}{\sigma_{\tilde{X}_{2}}}\right)=1-\Phi\left(\frac{c-\left(p_{b}+X_{1}+\gamma G\right)}{\sigma_{\tilde{X}_{2}}}\right)
$$

where $\Phi$ is the standard normal cumulative density function.

In probit models, we cannot know the real variance of the underlying variable $Y^{*}$ and instead fix it to 1 to identify the model (Greene, 2010). Hence, to solve equation 13 , we standardize $\tilde{X}_{2}$, setting $\sigma_{\tilde{X}_{2}}=1$, and, for simplicity, also $p_{b}=\mu_{\tilde{X}_{2}}=0$ :

$$
\operatorname{Pr}(Y=1)=1-\Phi\left(c-\left(X_{1}+\gamma G\right)\right)
$$

If $\operatorname{Var}\left(\tilde{X}_{2}^{0}\right)=\operatorname{Var}\left(\tilde{X}_{2}^{1}\right)$, callback probabilities will equal $1-\Phi\left(c-X_{1}\right)$ when $\mathrm{g}=0$ (non-minority), and $1-\Phi\left(c-X_{1}-\gamma\right)$ when $\mathrm{g}=1$ (minoritiy). Since $c-X_{1}-\gamma$ is higher than $c-X_{1}$ (remember than $\gamma$ will be negative if there is taste discrimination against minorities), non-minorities' selection probability will also be higher than minorities'. If there is no taste discrimination, $\gamma=0$, and the two probabilities will be the same. 
In contrast, suppose that employers perceive that the variance of candidates' unobservables differs in the two groups $\left(\operatorname{Var}\left(\tilde{X}_{2}^{0}\right) \neq \operatorname{Var}\left(\tilde{X}_{2}^{1}\right)\right)$. Heckman (1998) shows that selection probabilities would then generally differ for each. To see this, specify equation 13 above for each group. Because the denominators defining groups' variances differ, so do callback probabilities:

$$
\left[1-\Phi\left(\frac{c-\left(p_{b}+X_{1}\right)}{\sigma_{\tilde{X}_{2}}^{0}}\right)\right] \neq\left[1-\Phi\left(\frac{c-\left(p_{b}+X_{1}+\gamma\right)}{\sigma_{\tilde{X}_{2}}^{1}}\right)\right]
$$

except if:

$$
c-\left(p_{b}+X_{1}\right)=0 \text { and } \gamma=0
$$

or if:

$$
\gamma=\left(1-\frac{\sigma_{\bar{X}_{2}}^{1}}{\sigma_{\bar{X}_{2}}^{0}}\right) \cdot\left(c-\left(p_{b}+X_{1}\right)\right)
$$

Equation $15 \mathrm{~b}$ results from algebraically finding the value of $\gamma$ for which $\left(c-\left(p_{b}+X_{1}+\gamma\right)\right) / \sigma_{\tilde{X}_{2}}^{1}$ equals $\left(c-\left(p_{b}+X_{1}\right)\right) / \sigma_{\tilde{X}_{2}}^{0}$. It expresses how much higher or smaller minorities' scores in $Y^{*}$ are relative to nonminorities due to their belonging to a group with higher or lower variance, and the bias in estimating $\gamma$ (taste discrimination) when wrongly assuming variance equality.

Neumark (2012) proposed an equivalent formalization of the problem by making unobservables' variances a function of group membership in a heteroskedastic probit model:

$$
\sigma_{\tilde{X}_{2}}^{2}=\left(e^{k+\omega G}\right)^{2}
$$

with $\sigma_{\tilde{X}_{2}}^{0}=e^{k}$, and $\sigma_{\tilde{X}_{2}}^{1}=e^{k+\omega}$.

The callback probability expressed in 13 could then be re-expressed as: 


$$
\operatorname{Pr}(Y=1)=1-\Phi\left(\frac{c-\left(X_{1}+p_{b}+\gamma G\right)}{e^{k+\omega G}}\right)
$$

Standardizing 17 in relation to non-minorities' parameters, i.e., setting the mean $p_{b}=0$ and the standard deviation $\sigma_{\tilde{X}_{2}}^{0}=e^{k}=1$ (so that $\omega=0$ ), expression 15 could be rewritten as:

$$
\left[1-\Phi\left(c-X_{1}\right)\right] \neq\left[1-\Phi\left(\frac{c-\left(X_{1}+\gamma\right)}{e^{\omega}}\right)\right]
$$

Like 15 above, expression 18 states that callback probabilities differ for minorities and non-minorities, unless:

$$
c-X_{1}=0 \text { and } \gamma=0
$$

or:

$$
\gamma=\left(1-e^{\omega}\right) \cdot\left(c-X_{1}\right)
$$

Except for the normalizing assumption $p_{b}=0$, expression $18 \mathrm{~b}$ is equivalent to $15 \mathrm{~b}$, since $e^{\omega}=\sigma_{\tilde{X}_{2}}^{1} / \sigma_{\tilde{X}_{2}}^{0}$ (Neumark 2012). Both express the bias in $\gamma$ when ignoring differences in groups' standard deviations. Its magnitude and direction depends on: 1) how large minorities' standard deviation is relative to nonminorities' (on the coefficient $\omega$ defining the ratio $e^{\omega}$ of groups' standard deviations in $18 \mathrm{~b}$ ); and 2) how far the level of observables set by the experimenter is relative to employers' cutoff, as expressed in $c-$ $X_{1}$ in $18 \mathrm{~b}$.

\section{Distinguishing first-moment statistical discrimination from taste discrimination}

The solutions applied in the literature to distinguish first-moment statistical discrimination from taste discrimination take into account their typical definitions - see Guryan and Charles (2013) and Neumark (2016) for recent reviews of this work. Here we focus only on solutions using correspondence studies, but 
there have been other innovative approaches to separate statistical from taste discrimination that rely on lab experiments or a combination of field, lab experiments, and surveys (Anderson and Haupert 1999: Fershtman and Gneezy 2001; Levitt 2004: List 2004: Castillo and Petrie 2010; Masclet, Peterle, and Larribeau 2012; Zussman 2013; Lahey and Oxley 2016). The basic intuition behind these solutions, regardless of the methodology they employ, is that if taste discrimination is based on emotion and statistical discrimination rests on reason, only the latter could generate changes in employers' selection decisions when candidates' personal merits are experimentally manipulated, signaling that employers act rationally and react to the new information they receive.

As shown previously, in correspondence studies in which candidates are matched on observables, firstmoment statistical discrimination ensues when employers perceive that groups differ in average levels of $\tilde{X}_{2}$ unobservables, or if they think that the same unobservables contribute differently to productivity in each group, as expressed in coefficients $\delta$ and $\lambda$ in equation 9 presented above.

To estimate $\delta+\lambda$, the experimenter could add variables that are generally omitted in a CV (thus belonging to vector $\tilde{X}_{2}$ ) and calculate their effects on employers' group preferences, holding constant minority and non-minority members' observables through matching, randomization, or by hiding information on observables (Ahmed, Andersson, and Hammarstedt 2010; Bosch, Carnero, and Farré 2010; Kaas and Manger 2012: Drydakis 2014; Ewens, Tomlin, and Wang 2014; Carlsson and Eriksson 2017). Alternatively, and more economically, she could fix non-minorities' scores on $\tilde{X}_{2}$ (e.g., at their mean), manipulate experimentally minorities' scores on the same variables, and observe how much $\delta+\lambda$ change as a consequence, as in gender discrimination studies that assign typically masculine traits to some female candidates to assess their probability of being selected compared to an average woman (Weichselbaumer 2004; Keinert-Kisin, Hatzinger and Köszegi 2012). More formally:

$$
\delta+\lambda=\bar{P}^{1}-\bar{P}^{0}=\bar{Y}^{*, 1}-\bar{Y}^{*, 0}=\eta \tilde{X}_{2}^{1}
$$


where the superscripts 1 and 0 stand, respectively, for the minority and the non-minority.

In expression 19, $\eta$ expresses how much the groups' differences in productivities, and the corresponding differences in groups' appeal to employers, change as minorities' levels of unobservables are modified experimentally. It is a measure of how much employers allow minorities to compensate any group deficit/surplus with higher/lower personal unobservables, and hence, a measure of how much their discriminatory practice is grounded on perceptions about group differences in productivities. ${ }^{8}$ If $\eta=0$, $\delta+\lambda$ will also be 0 , and $\gamma^{\prime}$ in equation 7 will equal $\gamma$ in equation 10 , thus reflecting the constant penalty that minorities face due to employers' aversion towards them. If $\eta \neq 0$, first-moment discrimination is at place. ${ }^{9}$

The drawbacks of testing for $\eta=0$ are that it calls for more complicated and costly designs requiring the creation of multiple candidates' profiles with difficult to standardize traits. To avoid detection of the experiment, the tester may opt for randomizing the allocation of single applicants to different employers, rather than sending many fake CVs to the same employer, and to compare applicants' rates of response across, rather than within employers (Lahey 2008). While useful, this strategy may be difficult to implement in some contexts, as when job search engines require applicants to register online before they can apply to a job. An alternative is to reduce the number of applicants' profiles and send them to the same employer, but this will increase the probability of omitting relevant unobservables (Yinger 1998; Neumark 2016). If employers saw minorities and non-minorities as differing in these omitted

\footnotetext{
${ }^{8}$ Note that $\eta$ is not a measure of the absolute level of first-moment statistical discrimination experienced by minorities, but of how much it will be reduced per every additional unit of unobservables displayed by the candidate $\left(\eta=\left(\bar{P}^{1}-\bar{P}^{0}\right) / \tilde{X}_{2}^{1}\right)$

${ }^{9}$ Assuming, for simplicity at this moment, that there is no second-moment discrimination.
} 
characteristics, the tests devised to evaluate the presence of statistical discrimination might yield false negative results. ${ }^{10}$

Our recommendation is to vary minorities' levels of observables, under the premise that deficits/surpluses in productivities linked to unobservables can be offset with higher/lower observables (we show how to test this premise below). This solution respects Heckman's assumption that observables and unobservables are uncorrelated (that $X_{1} \perp \tilde{X}_{2}$ ), and instead assumes that at some level of $X_{1}$ and $\tilde{X}_{2}$ they are exchangeable and substitutable because they will have the same effect on productivities and hence also on groups' differences in productivities:

$$
\delta+\lambda=\eta \tilde{X}_{2}^{1}=\varphi^{\prime} X_{1}^{1}
$$

However, adding variation in minorities' $X_{1}$ observables will un-match minorities and non-minorities' levels of observables, making it impossible to tell, for example, if an equalization in the probability of being selected after raising minorities' observables captures the additional qualifications needed to overcome taste discrimination (the higher cutoff placed on minorities) or the substitution mechanisms between unobservables and observables characterizing first-moment statistical discrimination. In other words, insofar as $X_{1}$ and $G$ are correlated, $\varphi^{\prime}$ may also capture taste discrimination and be biased (hence the prime superscript).

Introducing variation in observables also in the majority group can control for differences between minority and majority members in observables. The experimenter could, for example, set two (or more) levels of observables for candidates applying to each job, sending more than two applications to each opening, and distinguish minority and majority members in each set - for precedents of multiple applications, see Bertrand and Mullainathan (2004); Booth, Leigh, \& Varganova (2012); or Ewens, Tomlin

10 See Zschirnt and Ruedin' meta-analysis (2016) for a recent summary of tests results. 
and Yang (2014). This means adding a coefficient $\beta$ to equation 10 above, and estimating the impact of $X_{1}$ observables on the underlying variable $Y^{*}$ measuring candidates' appeal to employers:

$$
Y_{i}^{*}=p_{b}+\beta X_{1}+(\delta+\lambda) G+\gamma G+\tau_{i}
$$

Adding the same variation in $X_{1}$ for both groups raises yet another problem, as it makes it impossible to generate the differences between minorities and non-minorities' productivities needed to assess employers' reactions. Only if the added variation in observables affected differently groups' appeal to the employers and their selection probabilities, it might be possible to use this interaction effect to assess firstmoment statistical discrimination. Ewens, Tomlin and Yang (2014) - see also Lahey (2008); Ahmed, Andersson, and Hammarstedt (2010) - argue that this interaction ought to be expected when there is statistical discrimination, but they ground their expectation on the presence of differences in the variances of groups' unobservables - i.e., on the presence of second-moment statistical discrimination - a scenario that we contemplate in the next section.

In contrast, we argue that an interaction effect between the level of observables and minority membership should also be expected in the absence of second-moment statistical discrimination, provided that employers select for further screening all (or the first $n$ ) candidates who pass a single productivity cutoff, regardless of by how much they exceed it. ${ }^{11}$ There is evidence that this selection model is widespread, especially in the first phase of multi-stage selection processes, and that it helps minorities to overcome deficits in some qualifications with surpluses in others (Sackett et al. 2001; De Corte, Lievens and Sackett 2007; Finch, Edwards, and Wallace 2009).

\footnotetext{
${ }^{11}$ This contrasts with Ewens, Tomline, and Yang (2014) who assume that employers call candidates in order of preferences.
} 
If the cutoff can be passed with different bundles of observables and unobservables because what matters to employers is that the selected candidates certify meeting an acceptable threshold of productivity, not how they reach it, then any perceived group differences in productivities would manifest in an interaction effect between the level of observables and group membership. The reason for this interaction effect is the censoring of candidates' productivities when they exceed the level $(c)$ of the cutoff required to be selected. This censoring makes employers assign the same potential productivity to all candidates who pass the cutoff - the one needed to pass it. It makes the difference in candidates' observables induced experimentally by the tester larger than the difference in candidates' productivities actually considered by the employer when selecting candidates $\left(\left(X_{1, \text { High }}-X_{1, \text { Low }}\right)>\left(P_{\text {High }}-P_{\text {Low }}\right)\right)$. This difference in differences is magnified when candidates have higher unobservables, since they will reach the cutoff sooner, all the more so, the more $\left(X_{1, H i g h}+\tilde{X}_{2}\right)>c$. It manifests in smaller returns to observables (smaller probabilities of selection) for candidates with higher unobservables - typically, non-minorities. Hence, the differences in candidates' appeal to employers produced by minorities and majority's differences in unobservables can be estimated unbiasedly by varying experimentally candidates' levels of observables. This can be formalized by eliminating the prime symbol for $\varphi$ and the superscript for $X_{1}^{1}$ in equation 20:

$$
\delta+\lambda=\eta \tilde{X}_{2}^{1}=\varphi X_{1}
$$

where $\varphi=\eta\left(\tilde{X}_{2}^{1} / X_{1}\right)$, i.e., the very same differences in candidates' appeal that were induced in equation 19 by altering the level of unobservables of the minority group, which is now expressed in terms of observables. Substituting $\varphi X_{1}$ for $\delta+\lambda$ in the prediction equation clarifies that $\varphi$ is the interaction effect between $X_{1}$ and $G$ capturing the selection adjustments that employers make as differences in minority and majority members' observables are made to vary experimentally, due to their perception that groups differ in unobservables. 


$$
Y_{i}^{*}=p_{b}+\beta X_{1}+\varphi X_{1} G+\gamma G+\tau_{i}
$$

As in the case of $\eta, \varphi$ can be zero, positive or negative. If $\varphi=0$, there is no first-moment statistical discrimination. If $\varphi<0$, employers believe that group differences in productivities linked to unobservables decrease as minorities' observables increase. Altonji and Perriet (2001) interpreted the wage corrections in favor of minority candidates with longer than average career histories as evidence that employers allow minorities to compensate deficits in unobservables with higher observables, and of first-moment statistical discrimination. If $\varphi>0$, employers believe that differences in productivities linked to unobservables become larger when minorities' observables increase. This could be because employers consider some low qualifications to increase productivity. For example, in some businesses, employers may favor non-empathetic workers who have no scruples for closing ethically dubious sales (DeLiedma, Yon and Wilber 2016). Alternatively, employers may discriminate more markedly against minorities with high qualifications because they consider such qualifications to be improper of a lowstatus group and a threat to the nonminority's higher status (Phillips, Rothbard, and Dumas 2009; Rudman et al. 2012). In both cases, employers' adjustments would be based on rational estimates of majority and minority's expected or prescribed productivities, rather than on negative feelings or prejudices against minorities, thus providing a valid test of first-moment statistical discrimination (Lahey 2008).

Equation 23 is the basis for calculating the penalty, in selection probabilities, that employers inflict on (non)minorities for each less unit of observables, if their deficits in unobservables are measured in these units. This adjustment can be obtained by calculating the partial effect or change in probability associated with $\varphi$ in expression 23, and by using the Delta method to derive standard errors (Norton, Wang and Ai 2004). These standard errors must be clustered within jobs, to allow for autocorrelation in employers' responses to the fake applications. 
To calculate the difference in the partial effect of belonging to a minority across levels of observables, we first restate equation 23 in terms of callback probabilities rather than propensities.

$$
\begin{gathered}
\operatorname{Pr}(Y=1)=\operatorname{Pr}\left(Y^{*}>c \mid X_{1}, \tilde{X}_{2}, G\right)=\operatorname{Pr}\left(p_{b}+\beta X_{1}+\varphi X_{1} G+\gamma G+\tau_{i}>c\right)= \\
\operatorname{Pr}\left(\tau_{i}>c-\left(p_{b}+\beta X_{1}+\varphi X_{1} G+\gamma G\right)\right)
\end{gathered}
$$

If we standardize and set $\tau_{i}=1$ and $p_{b}=0$, the equation for the partial effect of group membership is (Greene 2010):

$$
\frac{\partial \operatorname{Pr}(\mathrm{Y}=1)}{\partial \mathrm{g}_{\mathrm{i}}}=\varnothing\left(c-\left(\beta X_{1}+\varphi X_{1} G+\gamma\right)\right)-\varnothing\left(c-\beta X_{1}\right)
$$

where $\emptyset$ is the normal density function.

The interaction effect is the change in this partial effect across higher and lower levels of observables. If we treat group membership as a continuous variable, as we will do later for reasons to be explained, this interaction effect can be formalized as in Greene (2010): ${ }^{12}$

$$
\frac{\Delta \frac{\partial \operatorname{Pr}(\mathrm{Y}=1)}{\partial \mathrm{G}}}{\Delta_{X_{1}}}=\left[\varnothing\left(c-\left(\beta+\varphi X_{1} G+\gamma G\right)\right) \cdot\left(\gamma+\varphi X_{1}\right)\right]-[\varnothing(c-\gamma G) \cdot \gamma]
$$

The interaction effect is an estimate of first-moment statistical discrimination. Its interpretation depends on the sign of the coefficient $\varphi$. When $\varphi$ is negative, any discrimination (lower callback probabilities) faced by minorities will be smaller at higher levels of observables, indicating that employers adjust their

\footnotetext{
${ }^{12}$ For two categorical variables, the formula is:

$$
\frac{\Delta^{2} \operatorname{Pr}(\mathrm{Y}=1)}{\Delta_{\mathrm{G}} \Delta_{X_{1}}}=[\varnothing(c-(\beta+\gamma+\varphi))-\emptyset(c-\beta)]-[\varnothing(c-\gamma)-\emptyset(c)]
$$
}


selection decisions in their favor when candidates have higher levels of observables. If $\varphi$ is positive, minorities with above average levels of observables will be penalized even more by employers.

The interpretation of the baseline estimate of taste discrimination also depends on the sign of the interaction effect. If there is no interaction, the partial effect of group membership should be calculated using equation 25 for an (unobserved) candidate with average observables. The difference in groups' average callback probabilities driven by $\gamma$ could then be attributed to their baseline (and constant) difference in status.

If $\varphi<0$ and discrimination declines at higher levels of obervables, the partial effect should be calculated at this level using the first part of equation 26 (first set of terms within squared brackets). If the level is high enough (near, but not exceeding, the level beyond which over-qualification will make callback rates descend), it will provide an approximation to the maximum level of taste discrimination applied by employers.

If $\varphi>0$ and discrimination declines at lower levels of observables, the partial effect of group membership should be calculated at this lower level, using the terms in the second set of squared brackets in equation 26. Provided that it is low enough (but not lower than the minimum level required by the job, and not so low as to hamper the selection of enough candidates from all groups), it could also provide an approximation to the minimum level of taste discrimination exerted by employers.

This decomposition is valid only if the assumption that observables and unobservables are exchangeable holds. This can be tested by assessing the soundness of the threshold selection model described above. In this model all candidates passing a productivity cutoff on a composite measure are selected for further screening, regardless of by how much they exceed it, and thus can compensate deficits in some qualifications with surpluses in others. As noted, the cutoff shall generate an interaction effect between 
the level of observables and group membership whenever employers perceive that groups differ in productivity. If we could independently assess the validity of this model, the interaction effect could be more unambiguously interpreted as capturing first-moment statistical discrimination.

The introduction of variation in $X_{1}$ among candidates applying for the same job, combined with data on the order in which they are notified of having been selected, allows performing the test. If the threshold selection model held, this order (as determined, for example, by the date and time candidates receive the selection notification) should not vary with candidates' observables, or do it less than the probability of being selected. Differences between highly and lowly qualified candidates in the probability of being selected in first or second order vs. third or fourth order can be estimated with a probit model using the sub-pool of selected candidates, and compared with the inter-group differences in the probability of being selected, as estimated in another probit with all candidates. If the two models differed significantly and in the expected direction, the prevalence of a threshold model would be established and the interaction effect between observables and group membership could be more clearly linked to differences in groups' levels of unobservables.

\section{Neumark's method to estimate second-moment statistical discrimination}

The success of our method to separate first-moment statistical discrimination from taste discrimination depends on the estimate of the former not capturing differences in groups' variances instead of in their means. We have shown that when groups differ in their standard deviation, the estimate of taste+firstmoment statistical discrimination, and hence also of their decomposition, is biased. This could be avoided

by estimating the ratio $\sigma_{\tilde{X}_{2}}^{1} / \sigma_{\tilde{X}_{2}}^{0}$ of the standard deviations of the minorities to the nonminorities and estimating the other effects net of this ratio. 
We also showed that in order to estimate this ratio, experimenters must observe how groups' callback probabilities change as the distance $c-X_{1}$ between employers' cutoff and the level of observables set by the experimenter varies. Neumark (2012) ingeniously proposed introducing variation in $X_{1}$ observables among candidates in both groups to alter this distance and estimate second-moment statistical discrimination - see also Lahey (2008) for an antecedent.

This is the very same variation in candidates' observables we used above to separate taste from firstmoment statistical discrimination. The coincidence is unsurprising. The ratio $\sigma_{\tilde{X}_{2}}^{1} / \sigma_{\tilde{X}_{2}}^{0}$ of groups' standard deviations estimated in a heteroskedastic model where the variance of unobservables can differ between groups is just a re-parameterization of the interaction effect between group membership and level of observables that can be estimated in a standard probit (Neumark 2012; Rohwer 2015). Neumark assumes that group differences in the effects of candidates' observables can be attributed only to differences in their variances, thus providing a valid estimate of the latter. In the next section we discuss why we think this assumption is implausible, but before we describe Neumark's method to separate second-moment discrimination from the other two, which we will use later under different assumptions.

To make this separation, Neumark first estimates the difference $\beta_{0}$ in callback propensities (in z scores of $Y^{*}$ ) between candidates with lower and higher qualifications among non-minorities (hence the subscript 0). This allows observing how propensities change as the distance to employers' cutoff varies due to experimenter's decision to set candidates' observables at different levels. These changes cannot be taste or first-moment statistical discrimination, because they only affect non-minorities. Next, Neumark calculates the same difference $\beta_{1}$ between lowly and highly qualified candidates among minorities (hence, the subscript 1), which again is unaffected by taste or first-moment statistical discrimination. Because he assumes that the true effect of higher qualifications on callback probabilities is the same in both groups, $\beta_{0} / \beta_{1}$ will express how different is minorities' standard deviation from non-minorities': 


$$
\frac{\beta_{0}}{\beta_{1}}=\frac{\sigma_{\tilde{X}_{2}}^{1}}{\sigma_{\tilde{X}_{2}}^{0}}
$$

By moving unobservables' mean up or down employers' cutoff, experimenters can calculate the ratio $\sigma_{\tilde{X}_{2}}^{1} / \sigma_{\tilde{X}_{2}}^{0}$ independently of the effect $\gamma$ of taste+first-moment statistical discrimination, and estimate $\gamma$ without bias.

As Neumark (2012) shows, the same results ensue when running a heteroskedastic probit model that: 1) estimates the effect on callback probabilities of different levels of observables and group membership, and 2) considers the variance of unobservables' to differ across groups (see equation 17 above):

$$
\operatorname{Pr}(Y=1)=1-\Phi\left(\frac{c-\left(\beta X_{1}+\gamma G\right)}{e^{\omega G}}\right)
$$

Compared to the model shown before in equation 17 , the one in equation 28 contains one additional parameter $\beta$ estimating the effect of candidates' higher qualifications, and it has been standardized relative to the distribution of unobservables of the nonminorities $\left(p_{b}=0\right.$ and $\left.\sigma_{\tilde{X}_{2}}^{0}=1\right)$.

$\gamma$ and $\omega$ in equation 28 are a first test of the presence of taste+first-moment and second-moment statistical discrimination but, as noted by Neumark (2012: 1140), they are difficult to interpret, for the impact of one form of discrimination depends on the other. Being a minority affects $Y^{*}$ and callback probabilities both because minorities have a higher productivity cutoff to pass, and because they have a different variance. To solve this, Neumark (2012) proposes decomposing the partial effect of group membership on callback probabilities into two components capturing taste+first-moment and secondmoment statistical discrimination.

If group membership is treated as an interval rather than a categorical variable, the average partial effect of group membership in the heteroskedastic model 28 equals (Greene and Hensher 2010; Neumark 2012): 


$$
\frac{\partial \operatorname{Pr}(\mathrm{Y}=1)}{\partial \mathrm{g}_{\mathrm{i}}}=\varnothing\left(\frac{c-\left(\beta X_{1}+\gamma G\right)}{e^{\omega G}}\right) \cdot\left(\frac{\gamma-\omega \cdot\left(c-\left(\beta X_{1}+\gamma G\right)\right)}{e^{\omega G}}\right)
$$

where $\emptyset$ is the normal density function.

Neumark (2012: 1140) shows that expression 29 can be decomposed into two additive parts capturing the contributions of taste+first-moment and second-moment statistical discrimination to the total partial effect of group membership:

$$
\varnothing\left(\frac{c-\left(\beta X_{1}+\gamma G\right)}{e^{\omega G}}\right) \cdot\left(\frac{\gamma}{e^{\omega G}}\right)
$$

plus:

$$
\varnothing\left(\frac{c-\left(\beta X_{1}+\gamma G\right)}{e^{\omega G}}\right) \cdot\left(\frac{-\omega \cdot\left(c-\left(\beta X_{1}+\gamma G\right)\right)}{e^{\omega G}}\right)
$$

If $\gamma=0$ then $29 a=0$, and group membership's average partial effect captures the impact of groups' different variances, as estimated in 29 b, i.e., controlling for taste+first-moment statistical discrimination. Similarly, if $\omega=0$, then $29 \mathrm{~b}=0$ and the average partial effect captures taste+first-moment statistical discrimination, as estimated in 29a, i.e., controlling for second-moment statistical discrimination. For each component, standard errors and confidence intervals can be calculated with the Delta method (Cornelißen 2005).

As noted, Neumark assumes that the difference across groups in the effects of candidates' observables on callback propensities can be attributed exclusively to differences in their variances. He also argues that this assumption is testable (2012: 1139) provided other variables are added as controls to a standard probit model that includes all two-way interaction effects with group membership. If the ratios of the effects of these controls in the two groups were equal among themselves and equal to the ratio of the effect of candidates' levels of observables in each group (as established in a Wald test), the hypothesis 
that they are driven by the same ratio of the variances would be confirmed. However, as Neumark recognizes (2012: 1140), the validity of the test depends on the assumption that no other plausible reason may explain similarities in the ratios. We next argue that this reason does indeed exist.

\section{Disentangling the three forms of discrimination}

We argued above that when employers exert first-moment statistical discrimination they perceive groups as differing in average unobservables and act upon this perceptions. This should produce the same interaction effect between group membership and the level of observables proposed by Neumark to identify second-moment statistical discrimination. Hence, the level of observables cannot be used to estimate the ratio of groups' variances.

Instead, we propose using other variables which can also change the distance $c-X_{1}$ across groups needed to estimate the ratio. Rather than varying $X_{1}$ (which we reserve for estimating first-moment statistical discrimination) we propose varying $c$, i.e., the height of the cutoff used by employers to select candidates at different jobs. While experimenters cannot know beforehand the cutoff or selection ratio applied in each job, there are ways to approximate it.

First, the selection ratio (number of selected applicants relative to the number demanding it) could be estimated from the proportion of applicants selected for further screening within the pool of fake candidates applying to each job (in tight labor markets with low response rates, the number of fake candidates could be increased without matching them on observables, thus reducing the number of jobs with no callbacks). Alternatively, the ratio might be obtained from employers' direct responses to ad-hoc questions in the post-treatment surveys that often complement correspondence studies (Pager and Quilian 2005; Uggen et al. 2014). 
Second, the selection ratio could be estimated with the number of applications received by the employer at the time the experimenter sends her applications. Studies have shown that employers lower their selection ratio when there are more applicants (Schmidt and Hunter 1998; Le et al. 2007; Connerley 2013). In correspondence studies that use online job-search services, applicants' number is sometimes readily available in the job add. ${ }^{13}$ When unavailable, it might be approximated. Job search providers often publish quarterly or annual data on the numbers of applications processed by their engines in different occupations/sectors. ${ }^{14}$ These numbers could be assigned to all jobs applied to within the same occupations/sectors, and used as proxies of the number of applications received by each.

The ratio of the effect of the selection ratio on the probability of being selected in one group to the other will provide a valid estimate of the relative ratio of their variances only if the variable used to vary the cutoff is not a function of some omitted variable which also captures the difference between minorities and non-minorities' mean productivities, i.e., only if it does not capture first-moment discrimination. One such omitted variable could be the level of observables required in the job. It is reasonable to expect employers to increase their selection ratios and to differentiate less among candidates from different groups in jobs that require higher qualifications since there will be fewer applicants. Controlling for job's required levels of qualifications can solve this problem.

\footnotetext{
${ }^{13}$ This is the case of leading job search engines in Brazil, Italy, and Spain (InfoJobs) and of Reed.co.uk in the UK. However, in many of US, UK, France, China, or Sweden's search engines (e.g., Craiglist, Indeed, CareerBuilder, Monster, Jobijoba, 51jobs, Zhaopin, ChinaHR, Jobbsafari or Blocket ), this information is unavailable.

${ }^{14}$ For instance, in the USA Indeed publishes reports with job trends by sector based on average numbers of clicks. Monster publishes yearly reports on most searched 'words' (mainly referring to job sectors) in many of its country branches. Many providers also sell this information upon request.
} 
After selecting the variable $W$ providing variation in employers' cutoffs and the control $Z$ capturing that part of the variation unrelated to groups' relative variances, Neumark's method can be reapplied to estimate such variances. ${ }^{15}$ The ratio $\delta_{0} / \delta_{1}$ of the effects of the variable $W$ on $Y^{*}$ estimated in separate equations for minorities and non-minorities provides an estimate of the ratio $\sigma_{\tilde{X}_{2}}^{1} / \sigma_{\tilde{X}_{2}}^{0}$ of standard deviations in unobservables in each group. The ratio should be calculated separately for candidates with different levels of observables and for jobs requiring different qualifications, and the result averaged accordingly, so as to control for differences in the effects $\beta_{i}$ and $\vartheta$ of these variables. After calculating the ratio of the variances, the effects $\gamma$ and $\theta$ of taste and first-moment statistical discrimination can be estimated without bias. This is equivalent to running the following heteroskedastic model:

$$
\operatorname{Pr}(Y=1)=1-\Phi\left(\frac{c_{r}-\left(\delta W+\gamma G+\beta X_{1}+\theta X_{1} G+\vartheta Z+\rho Z G\right.}{e^{\omega G}}\right)
$$

If $W$ is standardized $c_{r}$ estimates the cutoff applied to jobs with average selection ratios. $\delta$ expresses how much this cutoff changes as the selection ratio varies, which helps estimate the ratio $e^{\omega}$ of the standard deviations of minorities to non-minorities. As above, the interaction effect $\theta$ tests for first-moment statistical discrimination. $\gamma$ provides an estimate of taste discrimination at baseline. Finally $\vartheta$ and $\rho$ are used as controls.

The total effect of group membership can be expressed as a change in probability and decomposed into its constitutive parts using Neumark's method (treating group membership as a continuous variable). Compared to the decomposition carried out in equations $29 \mathrm{a}$ and $29 \mathrm{~b}$ above, this one additionally estimates how group membership modifies the partial effect of candidates' levels of observables. We do it in two steps.

\footnotetext{
${ }^{15}$ The formalization can be generalized to vectors of $\mathbf{W}_{\mathbf{j}}, \mathbf{X}_{\mathbf{k}}$ and $\mathbf{Z}_{\mathbf{l}}$ variables measuring, respectively, jobs' characteristics, candidate's observabls, and the controls.
} 
First, we estimate the total partial effect of group membership to separate second-moment statistical discrimination from the other forms of discrimination and from the combined effect of group membership and the controls (if these were significant). If we set:

$$
c_{0}-\left(\delta W+\beta X_{1}+\gamma G+\theta X_{1} G+\vartheta Z+\rho Z G\right)=A
$$

then the partial or marginal effect is:

$$
\varnothing\left(\frac{A}{e^{\omega G}}\right) \cdot\left(\frac{\gamma}{e^{\omega G}}\right)+\emptyset\left(\frac{A}{e^{\omega G}}\right) \cdot\left(\frac{\theta X_{1}+\rho Z}{e^{\omega G}}\right)
$$

plus

$$
\varnothing\left(\frac{A}{e^{\omega G}}\right) \cdot\left(\frac{-\omega \cdot(A)}{e^{\omega G}}\right)
$$

where, as before, $\emptyset$ is the standard normal density function and probabilities are calculated at the means of all variables.

The first product $\left[\varnothing\left(\frac{A}{e^{\omega G}}\right) \cdot\left(\frac{\gamma}{e^{\omega G}}\right)\right]$ in expression 32 a estimates the change in callback probability associated with taste discrimination under the counterfactual that there is no statistical discrimination and that the partial effect of group membership does not change at different values of the controls (that $\theta=0$ and $\rho=0)$. Equation $32 \mathrm{~b}$ estimates changes in probability due to second-moment statistical discrimination under the counterfactual that there is neither taste nor first-moment statistical discrimination and that $\rho=0$. As before, standard errors and confidence intervals can be estimated with the Delta method.

Second, we estimate the interaction effect, or how much the change in callback probability induced by group membership changes with candidates' observables. If we treat $\mathrm{G}$ as an interval variable and set:

$$
c_{0}-\left(\delta W+\beta X_{1}+\gamma G+\theta X_{1} G+\vartheta Z+\rho Z G\right)=B
$$


and

$$
c_{0}-(\delta W+\gamma G+\vartheta Z+\rho Z G)=C
$$

and after rearranging terms, the formula for the interaction effect is:

$$
\frac{\Delta \frac{\partial \operatorname{Pr}(\mathrm{Y}=1)}{\partial \mathrm{G}}}{\Delta_{X_{1}}}=\left[\left\{\varnothing\left(\frac{B}{e^{\omega G}}\right) \cdot\left(\frac{\gamma}{e^{\omega G}}+\frac{\theta}{e^{\omega G}}+\frac{\rho Z}{e^{\omega G}}\right)\right\}-\left\{\varnothing\left(\frac{C}{e^{\omega G}}\right) \cdot\left(\frac{\gamma}{e^{\omega G}}+\frac{\rho Z}{e^{\omega G}}\right)\right\}\right]
$$

plus

$$
\left[\left\{\varnothing\left(\frac{B}{e^{\omega G}}\right) \cdot\left(\frac{-\omega \cdot(B)}{e^{\omega G}}\right)\right\}-\left\{\varnothing\left(\frac{-\omega \cdot(C)}{e^{\omega G}}\right) \cdot\left(\frac{C}{e^{\omega G}}\right)\right\}\right]
$$

Equation 35a provides an estimate of first-moment statistical discrimination but its interpretation depends on the sign of the interaction effect. If $\theta<0$, minorities experience lower levels of discrimination (smaller loss in probability) at higher levels of observables (assuming that $\omega=0$ and there is no secondmoment statistical discrimination). This means that employers adjust their selection decisions favorably to minority members who show higher qualifications than the "average" minority (that their personal qualifications can compensate group productivity deficits linked to unobservables). If $\theta>0$, minorities are more strongly discriminated against when they have higher observables, possibly because they threat non-minorities' higher status.

The estimate of the baseline level of taste discrimination depends on the sign of the interaction effect. If $\theta=0$, the baseline level of taste discrimination is the partial effect of group membership for an (unobserved) candidate with average observables, as provided by expression 32a (always under the counterfactual that $\omega=0$ and $\rho=0$ ). It expresses the constant penalty or stigma experienced by minorities. If $\theta<0$, the baseline level of taste discrimination is the partial effect of group membership for candidates with high levels of observables, as provided by the first part of expression 35 a. If $\theta>0$, 
the baseline level equals the partial effect of group membership for candidates with low levels of observables, as provided by the second part of expression 35a.

Finally, expression 35b shows how much do differences in callback probabilities between groups differ at higher and lower levels of observables because of groups' different variances. These differences will occur if both forms of statistical discrimination are present, because the selection threshold cuts across the normal distributions of unobservables at different points in each group.

\section{Application}

We now illustrate the applicability of the method using data from a correspondence study performed between May 2012 and February 2013 in Barcelona's metropolitan area. The study aimed at assessing discrimination against ex-prisoners in this labor market.

There is an ongoing scholarly debate about the penalty that ex-convicts suffer after release due to the stigma of their criminal records, especially when trying to find a job, and the possibly negative consequences on recidivism (Pager 2003). We aimed to contribute to this debate by assessing the degree and source of discrimination faced by males - who make up $93 \%$ of the prison population in Spain - in Barcelona's labor market. This market, the second in size in the country, is dominated by the manufacturing and tourist industries, and at the time of the study was suffering from a severe economic crisis resulting in unemployment rates of over $20 \%$. This had an effect on the rates of positive responses in the correspondence study, of only $6 \%$. 
Because of study's objectives, the sampling universe was restricted to the mid to low complexity jobs that typical (young, mid to lowly educated) male ex-convicts apply for, ${ }^{16}$ as reported in previous studies tracking ex-convicts' employment histories in the region (Alós-Moner et al. 2011).

Faked CVs were sent to a random sample of 601 job openings posted on a top online job search engine. Budget restrictions limited the sample size, especially since the correspondence study was only one of several other research activities dedicated to studying the impact of criminal records on ex-convicts.

Different from most correspondence studies, we sent four fake applications to each opening. One pair contained CVs with lower observables than the other. These varied according to job requirements but approximated a 'typical' ex-convict's profile (Alós-Moner et al. 2011) - compulsory secondary school and work experience in 5 short-term jobs. In contrast, the better qualified pair had high school degrees complemented with vocational education, and longer (6-years) and more continuous (3 long-term jobs) employment careers. Within each pair, one CV provided clear clues that the candidate had served time in prison (e.g., personal recommendations from prison officials/professionals or training certificates from penitentiary institutions). All four applications were sent in the same day. The application order and other traits of little substantial interest (e.g., photos, personal identifiers) were randomly assigned to applicants.

The dependent variable was whether or not the applicant was selected for further screening. We collected other valuable information on the applicant and the job offer. The main applicants' characteristics were fixed by design: having or not having criminal records and lower or higher observables. Job characteristics included the number of applicants who had applied to the job at the time the first fake application was sent and the number of openings available for that job - an information readily available from the job

\footnotetext{
${ }^{16}$ Examples are warehouse workers, industry operators, call agents, drivers, machinists, cookers, care workers, salesmen, and foremen.
} 
search engine. From both, we created a composite index, standardized in the analyses, measuring the number of applicants per opening. We also recorded if the level of education required for the job was above or below the median for all jobs. Finally, we recorded the sector/industry in which the job was categorized by the search engine. Table 2 displays basic descriptive statistics and the rates of callbacks received across variables' values.

\section{Table 1 around here}

Table 2 presents the study's main results. We focus on their methodological implications rather than their substantive interpretation. Standard errors for all models are clustered within jobs.

\section{Table 2 around here}

Model 1 shows the effect of having a prison record on the underlying variable $Y^{*}$ regulating callback probabilities, as estimated in a regular probit that has prison records as the main independent variable and applicant's level of observables, job's demand, and job's required level of education as controls. The coefficient for prison records is significant and negative, like the corresponding partial or marginal effect of prison records on the probability of being selected (-.03). From these results, we conclude that there is discrimination against male ex-convicts. Their probability of being selected is 3 percentage points lower than for non-ex-convicts. Since the estimated probability of being selected is of only .06 overall, the difference translates into a substantial penalty for ex-convicts - they are $1 / 3$ less likely to be called back for further screening. The difficulty lies in isolating the mechanism driving such discrimination, which we do in models 2 and 3.

Model 2 aims at separating first-moment statistical discrimination from taste discrimination, without considering that there may also be second-moment statistical discrimination. We do it by adding to the previous regular probit an interaction effect between criminal records and applicant's level of 
observables. We expect this interaction to provide a measure of how much employers rely on stereotypes about ex-convicts' productivities linked to unobservables to select them. The interaction is negative, pointing towards an intensification of discrimination at higher levels of observables, but small and nonsignificant, also when expressed as a change in probability.

Model 3 is a heteroskedastic probit that allows callback variances to differ by group. This helps estimate second-moment statistical discrimination and identify the other two forms of discrimination without bias. We add two interaction effects between criminal records, on the one hand, and candidates' observables and job educational requirements, on the other, to ensure that the estimate of the ratio of the variances is unaffected by employers' beliefs that deficits in unobservables can be offset or exacerbated with higher observables.

Since employers apply different selection ratios in different jobs and select different proportions of applicants in each (see Table 1), the group with higher dispersion has a relative advantage in jobs with higher selection ratios that give more opportunities to unusual applicants. Model 3 (like 1 and 2 before) shows that this group is made of ex-convicts, who have the highest relative variance (see row (10) in Table 3). Ex-convicts' variance is almost twice as large as the other applicants'. The estimate is only significant when expressed as a marginal change in probability (row (12)). We conclude that there is second-moment statistical discrimination and that ex-convicts benefit from it. The higher uncertainties that employers have about ex-convicts' unobservables play to the latter's advantage in jobs in which employers value more the unobserved qualifications of a candidate and increase their selection ratios to raise their chance to meet candidates with such unobservables. The effect is important. It increases ex-convicts callback probability by 9 percentage points ( 3 times their marginal probability).

Since there is heteroskedasticity, all estimates in models 1 and 2 were biased. The decomposition of taste and first-order statistical discrimination carried out in model 2 was also biased, if only slightly, as the 
interaction effect between criminal records and candidates' levels of observables, and the corresponding group differences in the partial effects of observables, remain non-significant in model 3.

The most marked change is in the estimate of taste discrimination at baseline. We provide two such estimates - one discarding (row (13)), and one considering (row (15)), the non-significant difference in the partial effect of criminal records at the two levels of observables. In both cases, the marginal effect is significant and negative. Ex-convicts experience taste discrimination. Its impact on their probability of being selected is important, as the penalty is more than 3 times the marginal penalty estimated for exconvicts in Model 1, which included all forms of (positive and negative) discrimination.

The results indicate that in the local market that we studied, employers discriminate against ex-convicts on moral grounds. Were it not because employers think that an average ex-convict is as productive as another based on their unobservables (although they can predict such productivity less accurately for exconvicts), and because in this market they give higher weight to unobservables, widening the range of candidates considered for an interview, the discrimination of ex-convicts on the grounds of their moral wrongdoings would be revealed in its true magnitude.

Table 3 shows the results of sensitivity analyses aimed at assessing the robustness of the findings and the plausibility of the assumptions on which they lie.

\section{Table 3 around here}

In model 4, we show the results of using a proxy for the number of applications per vacancy instead of the actual number to estimate the selection cutoff and the ratio of the variances of the two groups. As noted, many search engines omit this number in the job offer. However, they often publish reports on the number of applications processed in a term (typically a year) broken by sector. Our proxy assigns to each job the sum of the mean number of applications received by jobs in the same sector and year (in z scores 
times -1$)^{17}$ and of the proportion of callbacks received among the pool of applications sent to each job (also in z scores). The latter - we argued above - should increase as applications decrease. Row (12) of Table 3 reports the results of a Wald test comparing the fit of model 3 in Table 2, which uses the actual number of applications per vacancy, with that of model 4 in Table 3, which uses the proxy just described. The differences are not significant. We conclude that our method is robust to using aggregate information on the number of applications per sector.

In model 5, we re-estimate model 3 of Table 2 using another type of heterogeneous choice models - a heteroskedastic ordered probit (Williams 2009) - which corrects for the impact that omitting relevant independent variables has on the scaling of the variance at baseline in probit models (Mood 2010). It does so by re-estimating coefficients net of the value of the constant (Williams $2009 \& 2010$ ). Because we sent four CVs to each job and recorded the date and time when each applicant received a callback (if he did), we could generate a new dependent variable measuring the call order - from 0 (never called), to 4 (called in first place). Because there were very few cases in which all four fake applicants were selected, we recoded the variable into three values ( $1=$ never called, $2=$ called in fourth or third place, and $3=$ called in second or first place). As shown in model 5, while there are some changes in the estimates of the independent variables, they are minor, confirming that the results are robust.

In row (13) of Table 3 we report results from a homogeneity tests evaluating the assumption that the interaction effect between the number of applicants per opening and group membership is driving the ratio of the group variances calculated in model 3 of Table 1. If it did, as noted by Neumark (2012) and discussed before, the ratio of the effect of the number of applicants per opening among non-ex-convicts and ex-convicts should approximate the ratio of the effect of job's educational requirements in each group in the full two-way interaction probit model 6 of Table (this is just a reparametrization of the

\footnotetext{
${ }^{17}$ Data come from Infojobs-Esade (2013) annual report.
} 
heteroskedatic model run in model 3 of Table 2). Test results are reassuring since the differences are insignificant.

Finally, in row (14) of Table 3 we report the results of testing the validity of the threshold model of selection, one where candidates' merits are relevant for predicting their being selected but not the order in which they are selected. The results of the test are significant and in the expected direction, giving more credence to the interpretation that group differences in the effect of candidates' qualifications on their appeal to employers indicate the presence of first-order statistical discrimination.

\section{Summary and discussion}

In this paper, we discussed some important interpretative problems associated with correspondence studies aimed at measuring labor market discrimination, and proposed a comprehensive method to solve them. We reviewed and re-formalized the two problems that make it difficult to interpret minorities' typically lower selection rates as indicating that employers distaste them and apply a higher selection cutoff to them. First, lower rates may indicate that employers perceive minorities to have lower average productivities linked to unobservables, leading to first-moment statistical discrimination. Second, employers might perceive minorities to be more or less similar to each other in unobservables than nonminorities. Depending on which group is perceived as having higher variance and on how high do employers set the selection cutoff, higher or lower callback rates may ensue - a case of second-moment statistical discrimination.

Neumark (2012) proposed a solution to separate second-moment statistical discrimination from the other two by introducing variation in applicants' levels of observables. This variation, he argued, allows estimating the relative ratio of groups' variances in a heteroskedastic probit model. If employers selected larger proportions of applicants with higher observables, any relative differences across groups in how 
much or less candidates with different observables are likely to be selected should provide an estimate of the ratio of groups' variances and of second-moment statistical discrimination.

We questioned Neumark's reliance on variations in the intensity of discrimination at different levels of observables to estimate second-moment statistical discrimination, since these variations could also reflect employers' perceptions of groups' different average productivities linked to unobservables. Instead, we proposed to rely on variations in the intensity of discrimination across jobs differing in the number of applicants. This number has been shown to alter employers' selection ratios and the weight given to unobservables in their hiring strategies - higher when selecting more candidates for screening. Variations in the level of discrimination across jobs with different selection ratios help identify the group with the largest variance - the one benefitting the most from higher selection ratios - and estimate secondmoment statistical discrimination. The plausibility of alternative explanations can be tested using Neumark homogeneity test (2012).

In contrast, we relied on variations in the level of discrimination at different levels of observables to identify first-moment statistical discrimination. Such an interaction effect should be expected if employers selected for further screening all (or the first $n$ ) applicants that pass a minimum qualification threshold, rather than in order of qualifications, and if they thought that groups differ in productivities, as measured in some composite index where deficits in unobservables can be (partly) compensated with surpluses in observables. We proposed to test the plausibility of the threshold model of selection by observing if among the selected candidates those with higher qualifications are called first. If they did not, this would gives more credence to the claim that differences in the level of discrimination across candidates with different observables capture first-moment statistical discrimination.

Our main contribution has been to integrate both procedures into a unified heteroskedastic probit model that makes the variance a function of group membership. In this model, taste discrimination is estimated 
residually, as discrimination that cannot be accounted for by stereotypes about the distribution of unobservables across groups. We showed how to estimate it depending on the direction and intensity of the two forms of statistical discrimination.

Applying this method, we uncovered a credible story about the sources of discrimination against exconvicts in a local market. We showed that this discrimination was based on aversion (distaste) towards ex-convicts due to their past wrongdoings, not on higher uncertainties about their unobserved qualifications, which instead played to their advantage, and not on stereotypes about their average productivities, which were perceived to be similar to non-ex-convicts'. This has policy implications. Tackling distaste towards ex-convicts may be difficult and affect ex-convicts' chances of regaining a decent life and avoid reoffending. More research is necessary to ascertain if channeling ex-convicts towards jobs in which certified qualifications are less important, and where they have higher chances of being hired, could help overcome their stigma.

Our method to separate the three forms of discrimination can be improved by minimizing measurement and specification errors, especially since heteroskedastic models are notorious for magnifying them (Keele and Park 2006). First, the variables in the model could be better measured. The dependent variable could be measured ordinally, by reporting the call-back order of the candidates in designs that send more than two applications to each job, as we did in the sensitivity analyses. Applicants' observables could be measured on an interval scale, rather than as a dichotomy, making the test of the interaction effect between group membership and the level of observables less dependent on tester's choices.

Second, more variables could be added to better measure each form of discrimination. For example, in well budgeted studies, it might be possible to alternate different qualification across candidates applying to similar jobs, and test their contribution to explaining first-moment statistical discrimination. Other job characteristics could be used to construct proxies of jobs' selection ratios when the number of applicants 
in each is unavailable. We provided an example in the sensitivity analyses by using a proxy that combined the rate of callbacks obtained in each job with the average number of candidates applying for jobs in the same sector.

Third, miss-specification tests could also be refined. Neumark's homogeneity tests (2012), as he himself proposed, could be applied to subsets of controls which effects are unlikely to change across groups for reasons different to their variance, like some random variables used in the study (application order, pictures assigned to applicants, etc.). The test of the threshold model of selection could be complemented with another directly testing for the exchangeability of unobservables and observables. For example, the tester could add some unobservables to some candidates CV's and observe how their impact on selection probabilities changes as candidates' observables are experimentally modified.

While there is room for improvement, we hope to have contributed to strengthening the methodological foundations of correspondence studies and discrimination research. 


\section{References}

Ahmed, Ali M., Lina Andersson, and Mats Hammarstedt. 2010. "Can discrimination in the housing market be reduced by increasing the information about the applicants?." Land Economics, 86.1: 79-90.

Alós-Moner, Ramón, Fernando Esteban, Pere Jodar, Fausto Miguélez, Vanessa Alcaide, y Pedro LópezRoldan. 2011. "La inserció laboral dels exinterns dels centres penitenciaris de Catalunya." Documents de treball del Centre d'Estudis Jurídics i Formació Especialitzada (CEJFE). Barcelona: Centre d'Estudis d'Opinió i Formació Especialitzada (CEJFE).

Altonji, Jospeph G., and Charles R. Pierret. 2001. "Employer learning and statistical discrimination." The Quarterly Journal of Economics 116(1):313-350.

Anderson, Donna M., and Michael J. Haupert. 1999. "Employment and statistical discrimination: a handson experiment." The Journal of Economics 25(1):85-103.

Becker, Gary. S. 1971. "The Economics of Discrimination." $2^{\text {nd }}$ ed. Chicago: University of Chicago Press.

Bertrand, Marianne, and Sendhil Mullainathan. 2004. "Are Emily and Greg more employable than Lakisha and Jamal? A field experiment on labor market discrimination." The American Economic Review 94(4):991-1013.

Booth, Alison. L., Andrew Leigh, and Elena Varganova. 2012. “Does Ethnic Discrimination Vary across Minority Groups? Evidence from a field experiment." Oxford Bulletin of Economics and Statistics 74(4):547-573.

Bosch, Mariano, M. Angeles Carnero, and Lidia Farre. 2010. "Information and discrimination in the rental housing market: Evidence from a field experiment." Regional science and urban Economics, 40.1: 1119. 
Carlsson, M. and Eriksson, S. (2017) "The Effect of Age and Gender on Labor Demand. Evidence from a Field Experiment", Working paper series: Linnaeus University Centre for Discrimination and Integration Studies, 2017: 4.

Castillo, Marco, and Ragan Petrie. 2010. “Discrimination in the lab: Does information trump appearance?" Games and Economic Behavior 68(1):50-59.

Connerley, Mary L. 2013. "Recruiter Effects and Recruitment Outcomes." Pp. 21-34 in The Oxford Handbook of Recruitment, edited by K.Y.T. Yu and D.M. Cable. Oxford: Oxford University Press.

Cornelißen, Thomas. 2005. "Standard Errors of Marginal Effects in the Heteroskedastic Probit Model." Diskussionspapiere des Fachbereichs Wirtschaftswissenschafte no 320, Hannover: Universität Hannover.

Correll, Shelley. J., Stephen Benard, and In Paik. 2007. "Getting a Job: Is There a Motherhood Penalty?." American Journal of Sociology 112(5):1297-1339.

De Corte, Wifried, Filip Lievens, and Paul R. Sackett. 2007. “Combining predictors to achieve optimal tradeoffs between selection quality and adverse impact." Journal of Applied Psychology 92(5):1380-1393.

DeLiema, Marguerite, Yongjie Yon, and Kathleen H. Wilber. 2016. “Tricks of the trade: Motivating sales agents to con older adults." The Gerontologist 56(2):335-344.

Dymski, Gary. A. 2006. "Discrimination in the Credit and Housing Markets: Findings and Challenges." Pp.215-259 in Handbook on the Economics of Discrimination, edited by W.M. Rodgers. Northampton, MA: Edward Elgar Publishing.

Ewens, Michael, Bryan Tomlin, and Liang Choon Wang. 2014. "Statistical Discrimination or Prejudice? A Large Sample Field Experiment." Review of Economics and Statistics 96(1):119-134.

Fershtman, Chaim, and Uri Gneezy. 2001. "Discrimination in a segmented society: An experimental approach." The Quarterly Journal of Economics 116.1: 351-377. 
Finch, David M., Bryan D. Edwards, and J. Craig Wallace. 2009. “Multistage selection strategies: Simulating the effects on adverse impact and expected performance for various predictor combinations." Journal of Applied Psychology 94(2):318-340.

Greene, William. 2010. "Testing Hypotheses about Interaction Terms in Nonlinear Models." Economics Letters 107(2):291-296.

Greene, William H., and David A. Hensher. 2010. Modeling Ordered Choices: A Primer and Recent Developments. Cambridge: Cambridge University Press.

Guryan, Jonathan, and Kerwin K. Charles. 2013. "Taste-based or Statistical Discrimination: The Economics of Discrimination Returns to its Roots." The Economic Journal 123.572: F417-F43.

Heckman, James J. 1998. “Detecting Discrimination." Journal of Economic Perspectives 12(2):101-116.

Heckman, James J., and Peter Siegelman. 1993. "The Urban Institute Audit Studies: Their Methods and Findings", in Michael Fix and Raymond J. Struyk (Eds.): Clear and Convincing Evidence: Measurement of Discrimination in America. Washington, DC: The Urban Institute Press.

InfoJobs and ESADE. 2013. "Informe InfoJobs ESADE. Estado del mercado laboral en España". Retrieved November 82017 (https://nosotros.infojobs.net/wp-content/uploads/informe-infojobs-esade2012-1.pdf.

Kaas, Leo, and Christian Manger. 2012. "Ethnic discrimination in Germany's labour market: a field experiment." German economic review 13.1: 1-20.

Keele, Luke, and David K. Park. 2006. "Difficult Choices: An Evaluation of Heterogeneous Choice Models." Working Paper prepared for the 2004 Meeting of the American Political Science Association. 2nd version. Retrieved April 21, 2017. (http://www.nd.edu/ rwilliam/oglm/ljk-021706.pdf).

Keinert-Kisin, Christina, Reinhold Hatzinger, and Sabine T. Köszegi. 2012. "What's in a Name? a Personnel Selection Experiment on Gender Bias in Applicant Assessment." Paper presented at the EGOS (European Group of Organization Studies) Colloquium 2012, July 5, Helsinki, Sweden. Retrieved 
October 6, 2017 (https://www.semanticscholar.org/paper/What-s-in-a-Name-a-PersonnelSelection-Experiment-Keinert-Kisin-Hatzinger/650e60d93323d8644390ce621c8d8ccac3ab9a28).

Lahey, Joanna N. 2008. "Age, women, and hiring an experimental study." Journal of Human Resources 43(1):30-56.

Lahey, Joanna N., and Douglas Oxley. 2016. Discrimination at the intersection of age, race, and gender: Evidence from a lab-in-the-field experiment. National Bureau of Economic Research Working Paper Series, No. 25357.

Lang, Kevin, \& Lehmann, Jee-Yeon K. (2012). "Racial discrimination in the labor market: Theory and empirics." Journal of Economic Literature, 50(4), 959-1006.

Le, Huy, In-Sue Oh, Jonathan Shaffer, and Frank Schmidt. 2007. “Implications of Methodological Advances for the Practice of Personnel Selection: How Practitioners Benefit from Meta-analysis." The Academy of Management Perspectives 21(3):6-15.

Levitt, Stephen D. 2004. "Testing theories of discrimination: evidence from weakest link." Journal of Law and Economics 47(2):431-452.

List, John A. 2004. "The nature and extent of discrimination in the marketplace: Evidence from the field." The Quarterly Journal of Economics 119.1: 49-89.

Masclet, David, Emmanuel Pererle, and Sophie Larribeau. 2012. "The role of information in deterring discrimination: a new experimental evidence of statistical discrimination." (Working Paper No. 201238). Rennes: Center for Research in Economics and Management (CREM), University of Rennes 1, University of Caen and CNRS. Retrieved 6 October, 2017 (https://crem-doc.univrennes1.fr/wp/2012/201238.pdf).

Mood, Carina. 2010. "Logistic Regression: Why We Cannot Do What We Think We Can Do, and What We Can Do About It." European Sociological Review 26(1):67-82. 
Neumark, David. 2012. "Detecting Discrimination in Audit and Correspondence Studies." Journal of Human Resources 47(4):1128-1157.

— 2016. "Experimental research on labor market discrimination". National Bureau of Economic Research Working Papers Series, No. 22022.

Norton, Edward. C., Hua Wang, and Chunrong Ai. 2004. “Computing Interaction Effects and Standard Errors in Logit and Probit Models." Stata Journal 4(2):154-167.

Pager, Devah. 2003. "The Mark of a Criminal Record." American journal of sociology 108(5):937-975.

Pager, Devah, and Lincoln Quillian (2005). "Walking the talk? What employers say versus what they do." American Sociological Review 70(3):355-380.

Phillips, Katherine W., Nancy P. Rothbard, and Tracy L Dumas. 2009. "To disclose or not to disclose? Status distance and self-disclosure in diverse environments." Academy of Management Review 34(4):710732.

Rich, Judith. 2014. "What Do Field Experiments of Discrimination in Markets Tell Us? A Meta Analysis of Studies Conducted Since 2000", IZA Discussion Paper № 8584. Retrieved November 7, 2017 (https://ideas.repec.org/p/iza/izadps/dp8584.html).

Rohwer, Goetz. 2015. "A Note on the Heterogeneous Choice Model." Sociological Methods \& Research 44(1):145-148.

Rudman, Laura A., Corinne A. Moss-Racusin, Julie E. Phelan, Julie E., and Sanne Nauts. 2012. "Status incongruity and backlash effects: Defending the gender hierarchy motivates prejudice against female leaders." Journal of Experimental Social Psychology 48(1):165-179.

Sackett, Paul R., Neal Schmitt, Jill Ellingson, and Melissa B. Kabin. 2001. "High-stakes testing in employment, credentialing, and higher education: Prospects in a post-affirmative-action world." American Psychologist 56(4):302-318. 
Schmidt, Frank L., and John E. Hunter. 1998. "The validity and utility of selection methods in personnel psychology: Practical and theoretical implications of 85 years of research findings." Psychological bulletin 124(2):262-272.

Uggen, Chris, Mike Vuolo, Sarah Lageson, Ebony Ruhland and Hilary K. Whitham. 2014. "The Edge of Stigma: An Experimental Audit of the Effects of Low-Level Criminal Records on Employment." Criminology 52(4):627-654.

Weichselbaumer, Doris. 2004. "Is it sex or personality? The impact of sex stereotypes on discrimination in applicant selection." Eastern Economic Journal 30(2):159-186.

Williams, Richard. 2009. "Using Heterogeneous Choice Models to Compare Logit and Probit Coefficients across Groups." Sociological Methods \& Research 37(4):531-559.

_ 2010. "Fitting Heterogeneous Choice Models with OgIm." Stata Journal 10(4): 540-567.

Yinger, John. 1998. "Evidence on discrimination in consumer markets." Journal of Economic perspectives, 12.2: $23-40$.

Zschirnt, Eva, and Didier Ruedin. 2016. "Ethnic discrimination in hiring decisions: a meta-analysis of correspondence tests 1990-2015." Journal of Ethnic and Migration Studies, 42.7: 1115-1134.

Zussman, Asaf. 2013. "Ethnic discrimination: Lessons from the Israeli online market for used cars." The Economic Journal, 123.572: F433-F468. 


\begin{tabular}{lcccc}
\hline \hline & Prop. / Mean & St. Dev & $\begin{array}{c}\text { Proportion positive } \\
\text { responses }\end{array}$ & N (Applicants) \\
\cline { 2 - 5 } & 1.000 & .000 & .063 & 2320 \\
ison Records & & & & \\
Without & 0.500 & 0.500 & 0.077 & 1160 \\
With & 0.500 & 0.500 & 0.050 & 1160 \\
sher candidate's observable qualifications & & & & \\
Lower qualifications & 0.500 & 0.500 & 0.041 & 1160 \\
Higher qualiifications & 0.500 & 0.500 & 0.085 & 1160 \\
Imber of applications/vacancy & 79.7 & 158.7 & & \\
Above the mean & 0.259 & 0.438 & 0.020 & 600 \\
Below the mean & 0.741 & 0.438 & 0.078 & 1720 \\
sher educational-requirement job (binary) & & & & \\
$\quad$ Below the median requirements & 0.309 & 0.462 & 0.043 & 716 \\
Above the median requirements & 0.691 & 0.462 & 0.072 & 1604 \\
\hline \hline
\end{tabular}




\section{Coefficients}

(1) Constant

(2) Prison records

(3) Number of applications per vacancy (high to low)

(4) Candidate has higher observable qualifications

(5) Job has higher educational requirements

(6) Prison records*Candidate with higher observable qualifications

(7) Prison records*Job with higher educationalrequirements

Standard deviation estimates

(9) Ln of the ratio of the standard deviations (prison records to no prison records)

(10) Ratio of the standard deviations $\left(e^{\omega}\right)$

\section{Partial effects of prison records}

(11) Total

(12) Second-moment statistical discrimination, due to groups differing in variances

(13) Taste discrimination at baseline, assuming no statistical discrimination

(14) First-moment statistical discrimination (difference in partial effect at high vs. low levels of qualifications) assuming no second-moment

(15) Taste discrimination at baseline, assuming firstmoment but no second-moment statistical discrimination

\begin{tabular}{|c|c|c|c|c|c|}
\hline \multicolumn{2}{|c|}{ Model 1} & \multicolumn{2}{|c|}{ Model 2} & \multicolumn{2}{|c|}{ Model 3} \\
\hline Coeff. & $\begin{array}{l}\text { Std. } \\
\text { Error }\end{array}$ & Coeff. & $\begin{array}{l}\text { Std. } \\
\text { Error }\end{array}$ & Coeff. & $\begin{array}{l}\text { Std. } \\
\text { Error }\end{array}$ \\
\hline$-1.98 * * *$ & 0.141 & $-2.02 * * *$ & .144 & $-2.09 * * *$ & 0.175 \\
\hline$-0.22 * * *$ & 0.056 & $-0.15 * * *$ & .092 & -1.94 & 1.550 \\
\hline $0.78^{* *}$ & 0.247 & $0.79 * *$ & .248 & $1.05^{* *}$ & 0.321 \\
\hline $0.38^{* * *}$ & 0.069 & $0.43^{* * *}$ & .078 & $0.44^{* * *}$ & 0.079 \\
\hline \multirow[t]{5}{*}{0.22} & 0.146 & 0.22 & .146 & 0.2 & 0.161 \\
\hline & & -0.12 & .125 & 0.16 & 0.31 \\
\hline & & & & 0.24 & 0.323 \\
\hline & & & & 0.65 & 0.411 \\
\hline & & & & 1.92 & \\
\hline \multirow[t]{5}{*}{$-0.03 * * *$} & 0.007 & $-0.03^{* *}$ & .006 & 0.00 & 0.013 \\
\hline & & & & $0.08^{*}$ & 0.044 \\
\hline & & -0.01 & .006 & $-0.09 * *$ & 0.044 \\
\hline & & -0.00 & .014 & -0.01 & 0.013 \\
\hline & & & & $-0.07^{* *}$ & 0.035 \\
\hline
\end{tabular}

$\mathrm{N}=601$ job openings

4 applications and fake CVs were sent to each opening; one pair had lower qualifications than the other; within each pair, one CV included a prison record and the other did not.

Standard Errors are clustered within job applications

*Significant at the 0.06 level, **Significant at the 0.05 level, *** Significant at the 0.001 level

See text for further explanations 
Table 3: Sensitivity Analyses

\begin{tabular}{|c|c|c|c|c|c|c|c|c|c|}
\hline \multicolumn{2}{|c|}{$\begin{array}{l}\text { Heteroskedastic } \\
\text { Probit } \\
\end{array}$} & \multicolumn{2}{|c|}{$\begin{array}{c}\text { Heteroskedastic } \\
\text { Ordered Probit }\end{array}$} & \multicolumn{6}{|c|}{ Regular Probits } \\
\hline \multicolumn{2}{|c|}{ Model 4} & \multicolumn{2}{|c|}{ Model 5} & \multicolumn{2}{|c|}{ Model 6} & \multicolumn{2}{|c|}{ Model 7} & \multicolumn{2}{|c|}{ Model 8} \\
\hline Coeff. & $\begin{array}{l}\text { Std. } \\
\text { Error }\end{array}$ & Coeff. & $\begin{array}{l}\text { Std. } \\
\text { Error }\end{array}$ & Coeff. & $\begin{array}{l}\text { Std. } \\
\text { Error }\end{array}$ & Coeff. & $\begin{array}{l}\text { Std. } \\
\text { Error }\end{array}$ & Coeff. & $\begin{array}{l}\text { Std. } \\
\text { Error }\end{array}$ \\
\hline$-3.37^{* * *}$ & 0.516 & $0^{2}$ & & $-2.09 * * *$ & 0.175 & $-2.06 * * *$ & 0.151 & $-2.15^{*}$ & 1.245 \\
\hline \multirow[t]{2}{*}{-0.77} & 0.491 & -1.01 & 1.550 & 0.01 & 0.183 & -0.08 & 0.200 & 0.98 & 1.361 \\
\hline & & $0.95^{* *}$ & 0.325 & $1.06^{* *}$ & 0.321 & $1.05 * * *$ & 1.053 & 2.51 & 2.716 \\
\hline $1.67^{* * *}$ & 0.402 & $0.43^{* * *}$ & 0.080 & $.44 * * *$ & 0.079 & $0.38^{* * *}$ & 0.088 & -0.12 & 0.313 \\
\hline$-0.62^{* *}$ & 0.212 & 0.21 & 0.158 & 0.2 & 0.161 & 0.20 & 0.134 & -0.31 & 0.466 \\
\hline-0.63 & 0.496 & 0.02 & 0.233 & -0.13 & 0.124 & & & & \\
\hline-0.2 & 0.458 & 0.12 & 0.219 & 0.03 & 0.143 & 0.03 & 0.203 & 0.41 & 0.751 \\
\hline \multirow[t]{2}{*}{$1.22^{* *}$} & 0.316 & & & & & & & & \\
\hline & & & & $-0.51^{*}$ & 0.302 & 0.50 & 0.311 & -2.86 & 2.782 \\
\hline
\end{tabular}

Coefficients

(1) Constant

(2) Prison records

Less demanded job (fewer applications per

(3) vacancy)

(4) Candidate has higher observable qualifications

(5) Job has higher educational requirements Prison records*Candidates with higher

(6) qualifications Prison Records*Job with higher educational

(7) requirements

(8) Proxy for less demanded job ${ }^{1}$

(9) Prison records*Proxy for less demanded job

Standard deviation estimates

(10) $L n$ of the ratio of the standard deviations (CR to NCR' $0.48^{* *} \quad 0.152 \quad 0.36 \quad 0.337$

(11) Ratio of the standard deviations $\left(e^{\omega}\right)$

$1.61 \quad 1.44$

TESTS

Wald/t test Prob.

The models estimated with the actual and the approximated number of applications per vacancy are equivalent

(12) $\mathrm{H}_{0}$ : Fit of Model 4 in Table $3=$ Fit of Model 3 in Table 2

$0.43 \quad 0.513$

Neumark's homogeneity test: the ratio of the effect of the control variable in each group equals the ratio of the effect of \# of applicants in each group

(13) $\mathrm{H}_{0}:(3) /[(3)+(9)]$ in Model $6=(5) /[(5)+(7)]$ in Model 6

$1.06 \quad 0.302$

Threshold selection model test: Candidates' higher qualifications affect if they are selected but not the order in which they are selected (14) $\mathrm{H}_{0}$ : (4) in Model $8 \leq$ (4) in Model 7

$1.810 .035^{3}$

\footnotetext{
${ }^{1}$ Index created by adding the standardized scores of "Mean \# of yearly applications in jobs within the same sector" to the "\# of callbacks in each job applied for" times -1.

${ }^{2}$ Parameters estimate for higher cutoffs are available upon request.

${ }^{3}$ Probability for a directional $z$ test.

*Significant at the 0.10 level; **Significant at the 0.05 level; *** Significant at the 0.001 level
} 


\section{Author Biographies}

\section{Jorge Rodríguez-Menés}

Jorge Rodríguez-Menés is Serra Hunter Associate Professor of Sociology and Criminology at the Universitat Pompeu Fabra of Barcelona (Spain). He has a PhD in Sociology from Northwestern University (USA) and worked as Lecturer and Senior Lecturer in Sociology and Quantitative Methods at the Universities of Reading.

\section{Marti Rovira}

Marti Rovira is a Postdoctoral Research Fellow in the Department of Sociology and Nuffield College, at the University of Oxford. He holds a PhD in Law (Criminology) from Universitat Pompeu Fabra, and he is a Research Associate in the Criminology and Criminal Justice Research Group at that same university.

\section{Funding}

- Grant RecerCaixa 2013. "La regulación de los antecedentes penales". Funded by La Caixa and ACUP.

- Grant DER2015-64403-P. "Enforcement and supervision of sentences". Funded by the Spanish Ministry of Economy \& Competitiveness and FEDER (EU). 